\title{
What has been the progress in addressing financial risk in Uganda? Analysis of catastrophe and impoverishment due to health payments
}

Brendan Kwesiga ${ }^{1 *}$ D, Tom Aliti ${ }^{2}$, Pamela Nabukhonzo ${ }^{3}$, Susan Najuko², Peter Byawaka ${ }^{3}$, Justine Hsu ${ }^{4}$, John E. Ataguba ${ }^{5}$ and Grace Kabaniha ${ }^{6}$

\begin{abstract}
Background: Monitoring progress towards Universal Health Coverage (UHC) requires an assessment of progress in coverage of health services and protection of households from the impact of direct out-of-pocket payments (i.e. financial risk protection). Although Uganda has expressed aspirations for attaining UHC, out-of-pocket payments remain a major contributor to total health expenditure. The aim of this study is to monitor progress in financial risk protection in Uganda.

Methods: This study uses data from the Uganda National Household Surveys for 2005/06, 2009/10, 2012/13 and 2016/17. We measure financial risk protection using catastrophic health care payments and impoverishment indicators. Health care payments are catastrophic if they exceed a set threshold (i.e. 10 and 25\%) of the total household consumption expenditure. Health payments are impoverishing if they push the household below the poverty line (the US\$1.90/day and Uganda's national poverty lines). A logistic regression model is used to assess the factors associated with household financial risk.

Results: The results show that while progress has been made in reducing financial risk, this progress remains minimal, and there is still a risk of a reversal of this trend. We find that although catastrophic health payments at the $10 \%$ threshold decreased from $22.4 \%$ in $2005 / 06$ to $13.8 \%$ in $2012 / 13$, it increased to $14.2 \%$ in $2016 / 17$. The percentage of Ugandans pushed below the national poverty line (US\$1.90/day) has decreased from 5.2\% in 2005/ 06 to $2.7 \%$ in 2016/17. The distribution of both catastrophic health payments and impoverishment varies across socio-economic status, location and residence. In addition, certain household characteristics (poverty, having a child below 5 years and an adult above 60 years) are more associated with the lack of financial risk protection.

Conclusion: There is need for targeted interventions to reduce OOP, especially among those affected so as to increase financial risk protection. In the short-term, it is important to ensure that public health services are funded adequately to enable effective coverage with quality health care. In the medium-term, increased reliance on mandatory prepayment will reduce the burden of OOP health spending further.
\end{abstract}

Keywords: Financial protection, Uganda, Universal health coverage, Health financing, Health, Trends, Impoverishment, Catastrophic health payments

\footnotetext{
* Correspondence: kwesigab@who.int

${ }^{1}$ World Health Organization, Health Systems Cluster, Nairobi, Kenya

Full list of author information is available at the end of the article
}

C C The Author(s). 2020 Open Access This article is licensed under a Creative Commons Attribution 4.0 International License, which permits use, sharing, adaptation, distribution and reproduction in any medium or format, as long as you give appropriate credit to the original author(s) and the source, provide a link to the Creative Commons licence, and indicate if changes were made. The images or other third party material in this article are included in the article's Creative Commons. licence, unless indicated otherwise in a credit line to the material. If material is not included in the article's Creative Commons licence and your intended use is not permitted by statutory regulation or exceeds the permitted use, you will need to obtain permission directly from the copyright holder. To view a copy of this licence, visit http://creativecommons.org/licenses/by/4.0/ The Creative Commons Public Domain Dedication waiver (http://creativecommons.org/publicdomain/zero/1.0/) applies to the data made available in this article, unless otherwise stated in a credit line to the data. 


\section{Background}

Uganda has expressed aspirations to attain Universal Health Coverage (UHC) [1] - a key component of the Sustainable Development Goals (SDGs) agenda. UHC is about ensuring that the population has access to needed health services that are of adequate quality to be effective, without facing any financial risk that results from paying out-of-pocket (OOP) for health services [2-4]. Many countries, including Uganda, still face challenges to achieving UHC [5]. For example, in Uganda, OOP payments for health services are still dominant, contributing up to $40 \%$ of Uganda's total health expenditure [6], even though user fees/cost-sharing in government facilities have been abolished since 2001. This phenomenon presents a paradox [7].

Safeguarding households from incurring financial risks and minimising the risk of falling into poverty, through ensuring that households' consumption of other basic needs such as food and shelter are not compromised due to direct OOP payments is critical [3]. This is even more important for a country like Uganda, where more than a quarter of the population (about 10 million Ugandans) in absolute poverty [8] and more than $40 \%$ of the population remains vulnerable to economic shocks [9]. This situation raises an urgent need to implement health financing strategies that address the burden of OOP payments.

Financial resources to Uganda's health sector remain very inadequate. Government per capita health expenditure averaged US\$9 in the past ten years [10]. This is grossly below the US\$84 recommended to provide a minimum health care package [11] or the US\$271 per capita estimated for achieving UHC by 2030 [12]. Furthermore, the proportion of the health budget allocated to the health sector (an indication of the level of prioritisation of the sector) declined to an average of about 7\% in the period between 2015 and 2019 from about 9\% in 2010-2015 [10]. Low levels of public health financing led to the health sector, increasingly relying on OOP health spending and external resources [6].

It is not surprising that Uganda's Health Financing Strategy 2015-2025 identifies the need to address the current burden of OOP payments [13]. In designing such strategies to address financial risk in the context of moving towards UHC, there is a need for up-to-date country-specific evidence on the extent and distribution of the burden of OOP health spending across the population.

Adequately monitoring of $\mathrm{UHC}$ at both the global and country levels is required to harness the benefits of efforts towards UHC. To achieve this goal, the World Bank Group together with the World Health Organization (WB/WHO) have developed a framework for monitoring and evaluation of progress towards UHC [14]. This framework identifies two major indicators for monitoring financial risk protection-catastrophic health payments and impoverishing health expenditures. The catastrophic health payments indicator looks at the extent to which the share of OOP health payments in total household consumption expenditure does not compromise consumption of other household basic needs while the impoverishment indicator looks at the extent to which OOP payments increase both the incidence and intensity of poverty [14]. This framework also emphasizes the need to use several equity dimensions to monitor progress towards UHC.

Previous studies have analyzed financial risk protection in Uganda's health system $[15,16]$ using dated datasets. However, they do not show the trend in financial risk protection in Uganda using recent datasets, which is critical for monitoring progress towards the UHC goals. The objective of this paper is to present an updated assessment of financial risk protection in health using indicators from the WB/WHO framework. The paper also presents the trend from 2005/6 to 2016/17 to track Uganda's progress towards UHC. This study provides baseline information on the extent of financial risk protection in health as Uganda plans to roll out interventions including a national health insurance to decrease the reliance on OOP payments for health services and ensure financial risk protection for all.

\section{Methods}

\section{Data}

The Uganda integrated household survey, known as the Uganda National Household Survey (UNHS) is the main data for the analysis in this paper. The UNHS is undertaken every three or four years by the Uganda Bureau of Statistics (UBOS) and collects individual and household level data about socioeconomic characteristics, health status, health-seeking behaviour, and household expenditures including health expenditure. This paper uses the UNHS data for the years 2005/6, 2009/10, 2012/13 and 2016/17 containing data on 7400, 6887, 7500 , and 17,320 households, respectively. Stata version 13.1 [17] is used for data analysis.

\section{Measurement of socio-economic status}

Household consumption expenditure is used as the measure of socio-economic status as opposed to household income because the former is recommended as a more reliable measure of socioeconomic status in low-income countries like Uganda [18]. The construction of Uganda's consumption expenditure aggregate is detailed elsewhere [19]. Adult equivalent household consumption expenditure is obtained by dividing total household consumption by an adjusted household size (equivalence scale). The equivalence scale for Uganda is based on estimated calorie requirements for different age groups [19]. The consumption for household members below 18 years weighs less 
than that for adults in adjusting household expenditures. This approach for estimating the adjusted household size has been used elsewhere to assess both the catastrophic and the impoverishing effects of OOP health spending [16]. It is important to point out that using the equivalence scales as opposed to per capita approach (dividing household consumption expenditure by household size) results into different estimates of catastrophe and impoverishing effects.

\section{Measurement of catastrophic health payments}

Two thresholds are used to assess financial catastrophe from OOP health spending in this paper. A household's OOP spending on health services is defined as catastrophic if it exceeds $10 \%$ or $25 \%$ of total household expenditure (or consumption) [20]. Indicators of the incidence (headcount) and intensity (the mean positive gap) are considered. Catastrophic health payments headcount represents the percentage of household whose OOP payments for health exceed $10 \%$ or $25 \%$ of total household expenditure. On the other hand, the mean positive gap indicates by how much the households exceed the chosen threshold for those that exceed.

\section{Household characteristics associated with catastrophic health payments}

The factors that are associated with incurring catastrophic health expenditures are assessed using a logistic regression model.

$$
\text { cata }=\alpha+\beta X+\varepsilon
$$

where "cata" is the incidence of catastrophic health expenditures, cata $=1$ for a household with catastrophic expenditures, and 0 otherwise. The vector of explanatory variables $(X)$ includes equalised household size, the level of education, sex, employment status and marital status of the household head, location of household (rural or urban), presence of a child below 5 years and an adult above 60 years, and region of residence. The explanatory variables and expected signs are shown in Table 1.

\section{Measurement of impoverishment due to OOP health spending}

Impoverishment from OOP spending on health services captures the extent by which OOP payment affects both the incidence and the depth/intensity of poverty across the population [20,21]. Unlike the assessment of financial catastrophe, impoverishment headcount from paying OOP for health services estimates the difference between the percentage of the population below a defined poverty line before and after adjusting for the effect of OOP health payments [20]. The impoverishment gap from OOP spending is the difference in impoverishment gap (i.e. the extent to which an individual falls below the poverty line) before and after OOP health spending. The normalised impoverishment gap is computed by dividing the impoverishment gap by the poverty line-this is the impoverishment gap as a proportion of the poverty line.

Two poverty lines are used to assess impoverishment from OOP health spending. The first is the international poverty line (i.e. \$1.90/per day based on 2011 Purchasing Power Parity (PPP). ${ }^{1}$ The second is Uganda's national poverty line, which is region and location (urban/rural) specific. The average national poverty line is Shs. 29,505 but varies from Shs. 32,106 per month in the central region (urban) to Shs. 28,165 per month in the western region (rural). Uganda's national poverty line is constructed based on the calorie requirement of household members and then adjusted for household non-food expenditures ([19]).

\section{Results}

\section{Catastrophic health payments}

Table 2 indicates the trend of the catastrophic headcount and the mean positive gap for two thresholds (10 and 25\%). For both thresholds, there has been a decreasing pattern in terms of the catastrophic health payments headcount between 2005/06 and 2012/13. However, there was an increase between 2012/13 and 2016/17, irrespective of the thresholds. Concerning the mean positive gap, there has been a decreasing pattern for both thresholds, decreasing from 2005/06 to 2016/17.

Table 3 shows catastrophic payments disaggregated by social-economic status, urban/rural location, and region of residence. The incidence of catastrophic health expenditure was higher among the richer quintiles when compared to the poorest quintile in the first three years. The reverse was true in 2016/17, where the poorer quintiles experienced a higher incidence of catastrophic payments. The incidence of catastrophic costs was much higher in the rural areas than in the urban areas in 2005/06 and 2009/10 with the pattern changing in 2012/ 13 and 2016/17. With regards to the regions, catastrophic health payments are highest in the Western and Central regions between 2005 and 2017.

There are some household characteristics associated with an increased likelihood of catastrophic health payments. As shown in Table 4, the factors which are significantly associated (5\% level of significance) with an increased likelihood of catastrophic health expenditures are having a child, and an elderly member in the household.

${ }^{1}$ The PPP conversion rates for the different years surveys are; 2005/06 $(\mathrm{PPP}=513.9492), 2009 / 10(\mathrm{PPP}=741.3262), 2012 / 13$

$(\mathrm{PPP}=1043.083)$ and $2016 / 17(\mathrm{PPP}=1161.989)$ 
Table 1 Explanatory variables for the logistic regression

\begin{tabular}{ll}
\hline Variables & Expected sign \\
\hline Poverty (poor $=1$, non-poor $=0$ ) & + \\
Residence (urban $=1$, rural $=0$ ) & - \\
Region (reference $=$ central) & $+/-$ \\
Sex of household head (male $=1$, female $=0$ ) & $+/-$ \\
Number of people in the household & + \\
Children below 5 years in the household (yes $=1$, no $=0$ ) & + \\
Adults above 60 years in the household (yes $=1$, no $=0$ ) & + \\
Education of household head (reference: no formal education) & - \\
Employment (reference: formal employment) & - \\
Marital status (married $=1$, not married $=0)$ & $+/-$
\end{tabular}

+: Positive, -: Negative, +/-: Indeterminate

\section{Impoverishment}

The results in Tables 5 and 6 show the impoverishing effects of OOP payments in Uganda using the international poverty line (US\$1.91 per day) and the Uganda national poverty line respectively. The results show that OOP increase the incidence and depth/intensity of poverty among the poor. The pattern is similar for all the poverty lines considered. A decrease in the impoverishment headcount was observed from 2005/06 through to 2016/17, although the decline in the impoverishment headcount between 2012/13 and 2016/17 is minimal.

Table 7 shows the disaggregation of impoverishment effect by socio-economic status, residence and region. The results show that the impoverishment effect is mainly concentrated in the middle and second richest quintiles of socio-economic status. It is also largely concentrated in the Central and Western regions. The distribution of impoverishment by residence is less clearcut, showing a mixed pattern over the different years considered.

\section{Discussion}

This study set out to assess the trends in the status of financial protection in Uganda with a view of informing strategies for strengthening financial risk protection. The findings show that Ugandans still lack financial risk protection, and there has been a reversal of the trend in catastrophic expenditure and impoverishment rates. This pattern threatens Uganda's ability to attain UHC. This pattern is not surprising especially in the context of the country's dependence on OOP payments, which requires urgent attention. The main strength of this study is that unlike all the previous studies which showed a snapshot analysis of the situation of financial risk protection at a point in time, this study was able to show a trend over time. This paper also shows equity aspects by disaggregating the financial risk protection indicators using various equity dimensions. It also shows factors that are associated with households facing financial risk due to direct OOP payments.

The results from this study are consistent with previous assessments of financial risk protection in Uganda and other low-income countries that depend heavily on direct OOP payments $[15,16,22]$. However, when we compare the results of Uganda to similar studies in Kenya [23, 24], Rwanda, Zambia, South Africa, Tanzania and Ghana [25-27], Uganda's estimated levels of catastrophic payments and impoverishment are higher in magnitude than all these countries. However, the results are consistent with literature as countries, where the contribution of OOP payments in total health expenditure is higher, are more likely to have higher levels of financial catastrophe or impoverishment from OOP spending. The main difference between Uganda and the other countries is that it has a much higher level of OOP payments (at 40\%). In addition, these countries have significant prepayment from prepayment schemes

Table 2 Household catastrophic health payments

\begin{tabular}{|c|c|c|c|c|}
\hline \multirow[t]{2}{*}{ Year } & \multicolumn{2}{|l|}{$10 \%$} & \multicolumn{2}{|l|}{$25 \%$} \\
\hline & Headcount (\%) & Mean positive gap (\%) & Headcount (\%) & Mean positive gap (\%) \\
\hline $2005 / 06$ & 22.4 & 11.5 & 5.9 & 13.1 \\
\hline $2009 / 10$ & 21.4 & 11.0 & 5.4 & 12.2 \\
\hline $2012 / 13$ & 13.8 & 8.9 & 2.6 & 10.9 \\
\hline 2016/17 & 14.2 & 8.8 & 2.7 & 8.2 \\
\hline
\end{tabular}

Source: Authors' computation based on the UNHS 2005/06-2016/17 
Table 3 Disaggregation of catastrophic health expenditure (10\% of total household expenditure)

\begin{tabular}{|c|c|c|c|c|}
\hline Disaggregation variable & $2005 / 06$ & 2009/10 & 2012/13 & 2016/17 \\
\hline Total & 22.4 & 21.4 & 13.8 & 14.2 \\
\hline \multicolumn{5}{|c|}{ Socio-economic status quintiles } \\
\hline Poorest & 18.9 & 17.2 & 9.6 & 7.7 \\
\hline Second poorest & 20.4 & 18.9 & 10.0 & 13.7 \\
\hline Middle & 24.2 & 21.5 & 12.6 & 14.1 \\
\hline Second richest & 26.5 & 24.2 & 18.1 & 19.2 \\
\hline Richest & 22.0 & 25.0 & 18.7 & 16.5 \\
\hline \multicolumn{5}{|l|}{ Poverty Status } \\
\hline Non-poor & 23.7 & 22.6 & 14.8 & 14.7 \\
\hline Poor & 19.5 & 17.2 & 9.8 & 12.8 \\
\hline \multicolumn{5}{|l|}{ Residence } \\
\hline Rural & 23.5 & 21.7 & 13.5 & 15.3 \\
\hline Urban & 16.2 & 19.5 & 14.9 & 13.0 \\
\hline \multicolumn{5}{|l|}{ Region } \\
\hline Central & 20.3 & 21.9 & 19.8 & 15.3 \\
\hline Eastern & 21.1 & 21.6 & 9.1 & 13.0 \\
\hline Northern & 20.2 & 18.3 & 13.1 & 13.9 \\
\hline Western & 27.8 & 23.1 & 13.8 & 14.7 \\
\hline
\end{tabular}

that compliments the general tax contributions to health paid through government budgets.

The results of this study provide important implications for policymakers in Uganda. The fact that there could be a reversal in the gains observed in the reduction of financial risk highlights the importance of continuous monitoring. It also implies that there is a need to move away from the business as usual approach in Uganda. Although Uganda established free care policy for primary health care services by abolishing user fees, the allocation of resources to the health sector from the national budget has not matched the need. Establishing a well-intentioned policy mandate without adequately funding it may produce reverse results as is being experienced in Uganda where OOP payments have continued to increase even in the context of no user fees [7]. To highlight the extent of underfunding, whereas, consumer price index published by the UBOS shows that the price of consumables/utilities has increased by over $20 \%$ in the previous decade; the allocation to health facilities purchase of these has been stagnant (reduced in real terms when adjusted for inflation and exchange rate depreciation) [28]. This results in the lack of critical inputs required to provide quality health care in the public sector, leading to the private sector providing the majority of services [29]. This has led to inequitable access to services, as only those who can pay access services [30]. However, even for the non-poor who can pay for
Table 4 Determinants of catastrophic health expenditure, 2016/ 17

Catastrophic health expenditure (10\% of household expenditure)

\begin{tabular}{|c|c|c|c|c|c|c|}
\hline Independent Variables & $\begin{array}{l}\text { Odds-ratio } \\
\text { (OR) }\end{array}$ & SE. & z & $\begin{array}{l}P> \\
Z\end{array}$ & {$[959$} & $6 \mathrm{Cl}]$ \\
\hline $\begin{array}{l}\text { Poverty }(\text { poor }=1, \text { non- } \\
\text { poor }=0 \text { ) }\end{array}$ & 0.4 & 0.0 & -8.2 & 0.0 & 0.3 & 0.5 \\
\hline $\begin{array}{l}\text { Residence (urban }=1 \text {, rural }= \\
\text { 0) }\end{array}$ & 0.8 & 0.1 & -1.9 & 0.1 & 0.7 & 1.0 \\
\hline \multicolumn{7}{|l|}{ Region ( $R=$ central) } \\
\hline Eastern & 0.8 & 0.1 & -1.5 & 0.1 & 0.7 & 1.1 \\
\hline Northern & 0.9 & 0.1 & -0.6 & 0.6 & 0.8 & 1.2 \\
\hline Western & 0.8 & 0.1 & -1.6 & 0.1 & 0.7 & 1.0 \\
\hline Household size & 1.1 & 0.0 & 2.7 & 0.0 & 1.0 & 1 \\
\hline Sex of household head & 0.9 & 0.1 & -1.0 & 0.3 & 0.7 & \\
\hline
\end{tabular}

(male $=1$, female $=0$ )

Employment $(\mathrm{R}=$ formal)

$\begin{array}{lllllll}\text { Casual/Subsistence } & 1.1 & 0.1 & 0.5 & 0.6 & 0.9 & 1.3\end{array}$

$\begin{array}{lllllll}\text { Unemployed } & 1.3 & 0.2 & 1.9 & 0.1 & 1.0 & 1.6\end{array}$

Children below $\mathbf{5}$ (yes = 1, $\quad 1.3 \quad 0.1 \quad 3.1 \quad 0.0 \quad 1.1 \quad 1.5$ no $=0$ )

$\begin{array}{lllllll}\text { Adults above } \mathbf{6 0} \text { (yes }=\mathbf{1}, & 1.4 & 0.2 & 3.3 & 0.0 & 1.2 & 1.7\end{array}$ no $=0$ )

Education ( $R=$ no formal education)

$\begin{array}{lllllll}\text { Primary level } & 1.1 & 0.1 & 0.7 & 0.5 & 0.9 & 1.4 \\ \text { Secondary level } & 1.0 & 0.1 & -0.2 & 0.9 & 0.7 & 1.3 \\ \text { Tertiary } & 0.7 & 0.2 & -1.7 & 0.1 & 0.5 & 1.1 \\ \text { Marital status } & 1.3 & 0.2 & 2.0 & 0.0 & 1.0 & 1.7 \\ \text { married = 1, not married =0) } & & & & & & \\ \text { cons } & 0.1 & 0.0 & -13.5 & 0.0 & 0.1 & 0.2\end{array}$

Log pseudo likelihood $=-14,632,786$

Number of obs $=15,349$

Wald chi2 $(15)=135.0$

Prob $>$ chi $2=0.000$

Pseudo R2 $=0.013$

$\mathrm{R}=$ Reference category

Source: Authors' computation based on the UNHS 2016/17 data

services within the private sector, this approach is not sustainable in the long-term as they may be impoverished.

Increasing public financing would enable reduced exposure to financial risk, especially among the poor who pay OOP because of the limited availability of services in the public sector. Furthermore, one of the ways Uganda can reduce reliance on OOP payments is through moving towards mandatory health insurance. Uganda should fast track its plans for establishing a single pool 
Table 5 Impoverishment indicators using the international poverty line

\begin{tabular}{|c|c|c|c|}
\hline & $\begin{array}{l}\text { Pre-payment poverty (\%) } \\
\text { (A) }\end{array}$ & $\begin{array}{l}\text { Post-payment poverty (\%) } \\
\text { (B) }\end{array}$ & $\begin{array}{l}\text { Absolute difference (\%) } \\
\text { (B-A) }\end{array}$ \\
\hline \multicolumn{4}{|l|}{ 2005/06 (PPP = 513.9492) } \\
\hline Poverty headcount & 51.8 & 57.0 & 5.2 \\
\hline Normalised mean positive poverty gap & 35.2 & 37.0 & \\
\hline \multicolumn{4}{|l|}{ 2009/10 (PPP = 741.3262) } \\
\hline Poverty headcount & 46.3 & 50.8 & 4.5 \\
\hline Normalised mean positive poverty gap & 33.4 & 34.9 & \\
\hline \multicolumn{4}{|l|}{$2012 / 13(P P P=1043.083)$} \\
\hline Poverty headcount & 64.0 & 67.2 & 3.2 \\
\hline Normalised mean positive poverty gap & 39.4 & 40.2 & \\
\hline 2016/17 (PPP = 1161.989) & 51.8 & 57.0 & 5.2 \\
\hline Poverty headcount & 35.2 & 37.0 & \\
\hline Normalised mean positive poverty gap & & & \\
\hline
\end{tabular}

Source: Authors' computation based on the UNHS 2005/06-2016/17 data

mandatory national health insurance scheme so as to enable strategic purchasing of health care services and reduce direct OOP health payment at the point of care. However, this should be done concurrently with quality improvement interventions. It has also been shown in other countries that well-designed supply interventions aimed at improving quality of care are protective against OOP payments and have operational simplicity and greater provider accountability [31]. Moreover, the design of the insurance scheme also matters. It is recommended that that in a context such as Uganda, the a national health insurance scheme should mainly be funded through general taxes combined with adequately regulated insurance premiums as opposed to employment based contributions (i.e. labour taxes) [32].
This study is not without any limitations. The main limitation is the absence of information on access/utilization of services across the population for how financial risk was measured. The goal of UHC is to enable access to all who need care while minimizing the extent to financial risk. By not being able to show the extent to access, this paper did not show whether the lack of financial risk protection was influenced by the level of (or the lack of) access. Some additional limitations arise from the data used. Although the UNHS has critical data useful for this analysis, it has some major gaps that if addressed, would enable the survey to provide more useful information for decision-makers. For instance, one dimension that could be useful is to identify the type

Table 6 Impoverishment indicators using Uganda's national poverty line

\begin{tabular}{|c|c|c|c|}
\hline & $\begin{array}{l}\text { Pre-payment poverty (\%) } \\
\text { (A) }\end{array}$ & $\begin{array}{l}\text { Post-payment poverty (\%) } \\
\text { (B) }\end{array}$ & $\begin{array}{l}\text { Absolute difference (\%) } \\
\text { (B-A) }\end{array}$ \\
\hline \multicolumn{4}{|l|}{$2005 / 06$} \\
\hline Poverty headcount & 31.1 & 35.6 & 4.6 \\
\hline Normalised mean positive poverty gap & 35.2 & 37.0 & \\
\hline \multicolumn{4}{|l|}{$2009 / 10$} \\
\hline Poverty headcount & 23.2 & 27.2 & 4.0 \\
\hline Normalised mean positive poverty gap & 27.6 & 28.3 & \\
\hline \multicolumn{4}{|l|}{$2012 / 13$} \\
\hline Poverty headcount & 19.7 & 21.7 & 2.0 \\
\hline Normalised mean positive poverty gap & 26.4 & 26.7 & \\
\hline \multicolumn{4}{|l|}{$2016 / 17$} \\
\hline Poverty headcount & 21.5 & 24.1 & 2.7 \\
\hline Normalised mean positive poverty gap & 5.3 & 6.0 & \\
\hline
\end{tabular}

Source: Authors' computation based on the UNHS 2005/06-2016/17 data 
Table 7 Disaggregation of impoverishment headcount

\begin{tabular}{lllll}
\hline Disaggregation variable & $2005 / 06$ & $2009 / 10$ & $2012 / 13$ & $2016 / 17$ \\
\hline Total & 5.2 & 4.5 & 3.2 & 2.7 \\
$\begin{array}{l}\text { Socio-economic status quintiles } \\
\text { Poorest }\end{array}$ & 0.0 & 0.0 & 0.0 & 0.0 \\
Second poorest & 0.0 & 0.0 & 0.0 & 0.0 \\
Middle & 16.7 & 18.6 & 0.0 & 11.0 \\
Second richest & 8.3 & 2.5 & 14.9 & 2.5 \\
Richest & 1.0 & 1.5 & 1.2 & 0.0 \\
Residence & & & & \\
Rural & 5.6 & 4.9 & 2.9 & 3.1 \\
Urban & 2.9 & 2.2 & 4.1 & 1.6 \\
Region & & & & \\
Central & 5.4 & 3.4 & 4.8 & 2.5 \\
Eastern & 5.2 & 5.3 & 2.0 & 2.5 \\
Northern & 2.7 & 4.4 & 2.7 & 3.0 \\
Western & 6.9 & 4.9 & 3.4 & 3.0 \\
\hline
\end{tabular}

Source: Authors' computation based on the UNHS 2005/06-2016/17 data

of service (i.e. inpatient or outpatient) used and rate of utilization to identify the drivers of OOP payments for policy targeting.

\section{Conclusion}

In this study, we present empirical evidence on the extent of financial risk protection in health in Uganda. The financial burden due to OOP payments remains high and there is a risk of a reversal of previous gains in reducing this burden. We show that some households are more vulnerable to incurring the burden of OOP health payments. The study shows that Uganda needs to reconsider its strategies to decrease the burden of OOP payments. In particular, there is a need to fast-track the design and implementation of the mechanisms for protecting the population from financial catastrophe and impoverishment, especially the planned mandatory health insurance scheme. This should be done together with interventions aimed at improving effective coverage of quality health care in the public sector facilities. Lastly, monitoring financial risk protection should be institutionalised as part of monitoring the implementation of health financing reforms in Uganda.

\footnotetext{
Abbreviations

DFID: Department for International Development of United Kingdom; OOP: Out of Pocket Payments; PPP: Purchasing Power Parity;

SDGs: Sustainable Development Goals; UBOS: Uganda Bureau of Statistics; UHC: Universal Health Coverage; UNHS: Uganda National Household Survey; WB: World Bank; WHO: World Health Organisation
}

\section{Acknowledgements}

The Uganda Bureau of Statistics (UBOS) who conduct the Uganda National Household Survey is acknowledged for providing the data sets for analysis. Dr. Ben Nganda, Mr. Mayur Mandalia, Dr. Gabriela Flores and Dr. Tessa Edejer from the World Health Organization for the support extended towards making this paper possible. The draft of this paper was presented at the 5th Africa Health Economics Association Conference (AfHEA) in Accra, Ghana in March 2019 and at the International Health Economics Association Congress (iHEA) in Basel in July 2019. The feedback received from these sessions is greatly appreciated was critical in shaping this paper.

\section{Authors' contributions \\ Conceived and designed the study: BK, TA, PNK, SN, PB, JH and AEJ. Data cleaning and analysis: BK, TA, PNK, PB, AEJ, JH and GK. Drafted manuscript: BK, GK, TA and AEJ. Reviewed the manuscript: BK, TA, PNK, SN, PB and AEJ. All the listed authors have read and approved the final manuscript submitted for publication. \\ Funding \\ This study was possible through the support of Department for International Development (DFID) of United Kingdom. The funders had no role in the study.}

\section{Availability of data and materials}

The datasets analyzed in the current study are available from the Uganda Bureau of Statistics. UNHS data is available on the UBOS website (http:// www.ubos.org/unda/index.php/catalog/51). Data analysis files and other materials can be obtained from the corresponding author.

\section{Ethics approval and consent to participate}

The study did not involve or use human subjects or identifiable personal data, human tissue, or animals and thus did not require ethical approval. The study was implemented with the permission of and in collaboration with the Uganda Bureau of Statistics (UBOS) that implement the Uganda National Household Survey (UNHS)

\section{Consent for publication}

Not Applicable.

\section{Competing interests}

All authors declare no competing interests.

\section{Author details}

${ }^{1}$ World Health Organization, Health Systems Cluster, Nairobi, Kenya. ${ }^{2}$ Ministry of Health, Planning Department, Kampala, Uganda. ${ }^{3}$ Uganda Bureau of Statistics, Kampala, Uganda. ${ }^{4}$ World Health Organization, Economic Analysis Cluster, Geneva, Switzerland. ${ }^{5}$ Health Economics Unit, School of Public Health and Family Medicine, University of Cape Town, Cape Town, South Africa. ${ }^{6}$ World Health Organization, Health Systems Cluster India Country Office, New Delhi, India.

Received: 17 December 2019 Accepted: 2 July 2020

Published online: 12 August 2020

\section{References}

1. Ministry of Finance, Planning and Economic Development. National Development Plan 2015-2020. Kampala: Ministry of Finance, Planning and Economic Development; 2015.

2. World Health Organization. The world health report 2013: research for universal coverage. Geneva: World Health Organization; 2013.

3. World Health Organization. The world health report 2010 - health systems financing: the path to universal coverage. Geneva: World Health Organization; 2010.

4. Ataguba JE, Ingabire M-G. Universal health coverage: assessing service coverage and financial protection for all. Am J Public Health. 2016;106(10): 1780-1

5. Mclntyre D, Obse AG, Barasa EW, Ataguba JE. Challenges in financing universal health coverage in sub-Saharan Africa. Oxford Res Encyclopedia Economics Finance. 2018;2018(5):1-80.

6. Ministry of Health. National Health Accounts 2012/13 and 2013/14. Kampala: Ministry of Health; 2016.

7. Nabyonga Orem J, Mugisha F, Kirunga C, Macq J, Criel B. Abolition of user fees: the Uganda paradox. Health policy and planning. 2011;26(suppl_2):ii41-51.

8. Uganda Bureau of Statistics. Uganda National Household Survey 2016/17. Kampala: Uganda Bureau of Statistics; 2017. 
9. World Bank. The Uganda poverty assessment report 2016 farms, cities and good fortune: assessing poverty reduction in Uganda from 2006 to 2013. Kampala: The World Bank; 2016.

10. Ministry of Health. Annual Health Sector Performance Report. Kampala: Ministry of Health; 2017.

11. McIntyre D, Meheus F. Fiscal Space for Health and Other Social Services. London: Chatam House; 2014.

12. Stenberg $K$, Hanssen $O$, Edejer TT-T, Bertram M, Brindley C, Meshreky A, Rosen JE, Stover J, Verboom P, Sanders RJTLGH. Financing transformative health systems towards achievement of the health sustainable development goals: a model for projected resource needs in 67 low-income and middle-income countries. Lancet Glob Health. 2017;5(9):e875-87.

13. Ministry of Health. Health Financing Strategy 2015-2025. Kampala: Ministry of Health, Uganda; 2016.

14. Boerma T, Eozenou P, Evans D, Evans T, Kieny M-P, Wagstaff A. Monitoring progress towards universal health coverage at country and global levels. PLoS Med. 2014;11(9):e1001731.

15. Xu K, Evans DB, Kadama P, Nabyonga J, Ogwal PO, Nabukhonzo P, Aguilar AM. Understanding the impact of eliminating user fees: utilization and catastrophic health expenditures in Uganda. Soc Sci Med. 2006;62(4):866-76.

16. Kwesiga B, Zikusooka CM, Ataguba JE. Assessing catastrophic and impoverishing effects of health care payments in Uganda. BMC Health Serv Res. 2015;15(1):30.

17. StataCorp. Stata: release 13 - Statistical software. College Station, Texas: StataCorp LP; 2013.

18. Deaton A, Zaidi S. Guidelines for constructing consumption aggregates for welfare analysis, vol. 135. Washington DC: World Bank Publications; 2002

19. Appleton S. Poverty in Uganda, 1999/2000: preliminary estimates from the UNHS. Nottingham: University of Nottingham; 2001.

20. Wagstaff A, Ev D. Catastrophe and impoverishment in paying for health care: with applications to Vietnam 1993-1998. Health Econ. 2003;12(11):921-33.

21. Foster J, Greer J, Thorbecke E. The Foster-Greer-Thorbecke (FGT) poverty measures: 25 years later. J Econ Inequal. 2010;8(4):491-524.

22. Ruhweza M, Baine SO, Onama V, Basaza V, Pariyo G. Financial risks associated with healthcare consumption in Jinja, Uganda. Afr Health Sci. 2009;9(Suppl 2):S86-9.

23. Barasa EW, Maina T, Ravishankar N. Assessing the impoverishing effects, and factors associated with the incidence of catastrophic health care payments in Kenya. Int J Equity Health. 2017;16(1):31.

24. Chuma J, Maina T. Catastrophic health care spending and impoverishment in Kenya. BMC Health Serv Res. 2012;12(1):413.

25. Akazili J, Ataguba JE-O, Kanmiki EW, Gyapong J, Sankoh O, Oduro A, McIntyre D. Assessing the impoverishment effects of out-of-pocket healthcare payments prior to the uptake of the national health insurance scheme in Ghana. BMC Int Health Hum Rights. 2017;17(1):13.

26. Mills A, Ataguba JE, Akazili J, Borghi J, Garshong B, Makawia S, Mtei G, Harris B, Macha J, Meheus F. Equity in financing and use of health care in Ghana, South Africa, and Tanzania: implications for paths to universal coverage. Lancet. 2012;380(9837):126-33.

27. Nguyen $H T$, Rajkotia $Y$, Wang $H$. The financial protection effect of Ghana National Health Insurance Scheme: evidence from a study in two rural districts. Int J Equity Health. 2011;10(1):4.

28. Ministry of Health. Ministerial Policy Statement for FY 2018/19. 2018 Kampala: Ministry of Health.

29. Konde-Lule J, Gitta SN, Lindfors A, Okuonzi S, Onama VO, Forsberg BC. Private and public health care in rural areas of Uganda. BMC Int Health Hum Rights. 2010;10(1):29.

30. Kwesiga B, Ataguba JE, Abewe C, Kizza P, Zikusooka CM. Who pays for and who benefits from health care services in Uganda? BMC Health Serv Res. 2015;15(1):44.

31. Wagner N, Quimbo S, Shimkhada R, Peabody J. Does health insurance coverage or improved quality protect better against out-of-pocket payments? Experimental evidence from the Philippines. Soc Sci Med. 2018. https://doi.org/10.1016/j.socscimed.2018.03.024.

32. Yazbeck AS, Savedoff WD, Hsiao WC, Kutzin J, Soucat A, Tandon A, Wagstaff A, Chi-Man Yip W. The case against labor-tax-financed social health insurance for low- and low-middle-income countries. Health Affairs (Project Hope). 2020;39(5):892-7. https://doi.org/10.1377/hlthaff.2019.00874.

\section{Publisher's Note}

Springer Nature remains neutral with regard to jurisdictional claims in published maps and institutional affiliations.
Ready to submit your research? Choose BMC and benefit from:

- fast, convenient online submission

- thorough peer review by experienced researchers in your field

- rapid publication on acceptance

- support for research data, including large and complex data types

- gold Open Access which fosters wider collaboration and increased citations

- maximum visibility for your research: over $100 \mathrm{M}$ website views per year

At $\mathrm{BMC}$, research is always in progress.

Learn more biomedcentral.com/submissions 